\title{
The Fight for Digital Sovereignty: What It Is, and Why It Matters, Especially for the EU
}

\section{Luciano Floridi $^{1,2}$}

Published online 12 August 2019

(C) Springer Nature B.V. 2020

Digital sovereignty seems to be something very important, given the popularity of the topic these days. True. But it also sounds like a technical issue, which concerns only specialists. False. Digital sovereignty, and the fight for it, touch everyone, even those who do not have a mobile phone or have never used an online service. To understand why, let me start with four episodes. I shall add a fifth shortly.

June 18, 2020: The British government, after having failed to develop a centralised, coronavirus app not based on the API provided by Google-Apple, ${ }^{1}$ gave up, ditched the whole project (Burgess 2020) and accepted to start developing a new app in the future that would be fully compatible with the decentralised solution supported by the two American companies. This U-turn was not the first: Italy (Longo 2020) and Germany (Busvine and Rinke 2020; Lomas 2020) had done the same, only much earlier. Note that, in the context of an online webinar on COVID-19 contact tracing applications, organised by RENEW EUROPE (a liberal, pro-European political group of the European Parliament), Gary Davis, Global Director of Privacy \& Law Enforcement Requests at Apple (and previously Deputy Commissioner at the Irish Data Protection Commissioner's Office), stated that

"Google/Apple can disable the system [i.e. the contact tracing app, my text] on a regional basis when no longer needed". 2

This is power as control, as I shall explain presently, and it is clear who has it and who can exercise it, as far as the coronavirus apps and the API are concerned. ${ }^{3}$

\footnotetext{
${ }^{1}$ Disclosure: the author was a member of the Ethics Advisory Board for the NHSX app.

${ }^{2}$ See YouTube video at time 1:14:13, https://re.livecasts.eu/webinar-on-contact-tracing-applications/program ${ }^{3}$ Part of the failure was also a failure in trust; on the ethical issues sorrouding the coronavirus apps see (Morley et al. 2020).
}

Luciano Floridi

luciano.floridi@oii.ox.ac.uk

1 Oxford Internet Institute, University of Oxford, 1 St Giles, Oxford OX1 3JS, UK

2 The Alan Turing Institute, 96 Euston Road, London NW1 2DB, UK 
July 7, 2020: Mike Pompeo, the US Secretary of State, announced the intention of his government to ban TikTok (Clayton 2020). India had already banned it (Singh 2020) together with tens of other Chinese apps, including WeChat, following clashes at the India-China border in the Himalayas. TikTok is an app to create and share amateur music videos of a few seconds. Translated into 40 languages, it has over 800 million active users every month. Something used to enjoy singing, dancing, comedy, and lipsyncing short videos would seem harmless. However, the videos may contain social or political messages, for example. And the fear is that the app can collect personal data, including sensitive metadata, such as user geolocation, and may be used to support China's espionage and infiltration, hence the possible ban. However, things may soon change. At the time of writing, Microsoft announced that:

"Following a conversation between Microsoft CEO Satya Nadella and President Donald J. Trump, Microsoft is prepared to continue discussions to explore a purchase of TikTok in the United States. Microsoft will move quickly to pursue discussions with TikTok's parent company, ByteDance, in a matter of weeks, and in any event completing these discussions no later than September 15, 2020. During this process, Microsoft looks forward to continuing dialogue with the United States Government, including with the President. The discussions with ByteDance will build upon a notification made by Microsoft and ByteDance to the Committee on Foreign Investment in the United States (CFIUS). The two companies have provided notice of their intent to explore a preliminary proposal that would involve a purchase of the TikTok service in the United States, Canada, Australia, and New Zealand and would result in Microsoft owning and operating TikTok in these markets. Microsoft may invite other American investors to participate on a minority basis in this purchase." August 2, 2020, Microsoft Corporate Blogs. ${ }^{4}$

July 16: The Court of Justice of the European Union (EU) concluded that the US do not offer sufficient guarantees about the surveillance and the security of personal data, and therefore invalidated the EU-US Data Protection Shield, the agreement that regulates the transfer of the data of European users to processors in the US for commercial purposes. $^{5}$

July 20, 2020: Huawei is a leading Chinese company in the production of $5 \mathrm{G}$ networks and systems. If the EU will ban the use of its technology for security reasons, following in this the US and Great Britain, then China threatened that it may retaliate against two European companies, Nokia and Ericsson (Mukherjee 2020).

These are just a handful of examples, during some ordinary weeks in the life of the digital revolution. They could be multiplied, the reader may have others in mind, and I shall refer to one more in a moment. But the common thread that unites them is getting clear: these are all episodes in the fight for digital sovereignty, that is, for the control of data, software (e.g. AI), standards and protocols (e.g. 5G, domain names), processes (e.g. cloud computing), hardware (e.g. mobile phones), services (e.g. social media, e-

\footnotetext{
${ }^{4}$ https://blogs.microsoft.com/blog/2020/08/02/microsoft-to-continue-discussions-on-potential-tiktokpurchase-in-the-united-states/

${ }^{5}$ https://curia.europa.eu/jcms/upload/docs/application/pdf/2020-07/cp200091en.pdf
} 
commerce), and infrastructures (e.g. cables, satellites, smart cities), in short, for the control of the digital. Let me clarify that by "control" I mean here the ability to influence something (e.g. its occurrence, creation, or destruction) and its dynamics (e.g. its behaviour, development, operations, interactions), including the ability to check and correct for any deviation from such influence. In this sense, control comes in degrees and above all can be both pooled and transferred. This is crucial since we shall see that the ultimate form of control is individual sovereignty, understood as selfownership, especially over one's own body, choices, and data.

The fight for digital sovereignty is an epochal struggle not only of all against all, but also of anyone allied with anyone, with variable alliances changing according to interests and opportunities. The most visible clash is between companies and states, and it is asymmetric. On the one hand, companies design, produce, sell, and maintain the digital. This poietic (that is, creative) power over the digital means that states depend on companies for almost anything that is digital, to the extent that, for example, companies have, in some contexts, become the first line of defence when it comes to cyber-attacks. On the other hand, states have the power to regulate the digital, and this is a powerful form of cybernetic (in the original, Greek sense of piloting or steering ${ }^{6}$ ) control, exercised by determining what is legal or not, incentives and disincentives, kinds and levels of taxation, policies for public procurement, as well as modalities and costs of compliance. The usual narrative that regulations could stifle or even kill innovation and destroy whole industrial sectors is also an acknowledgement of the power of the cybernetic State. It is a significant counterbalance to the other narrative, about the impossibility of regulating the digital because states and regulations arrive always too late with respect to the fast-moving companies and their nimble operations. The real point is that, between companies and states, the former can determine the nature and speed of change, but the latter can control the direction of change.

In this asymmetric dialectic, sometimes states use domestic companies for political ends, to fight other states. Companies may try to trick or bypass states and their legislation, but they also rely on "home" states to defend them against foreign states which oppose them. And sometimes companies fight with their own "home" states, as it is the case with the Twitter-Trump clash (Posner 2020). Finally, companies may fight against each other. For example, Microsoft lost against Google in the competition for hegemony over the search business $(2.44 \%$ vs. $91.54 \%$ of market share respectively, in $2020^{7}$ ); but won an important victory against Amazon, IBM, and Oracle for the hegemony over cloud computing by securing the US Department of Defense cloud computing contract (Joint Enterprise Defense Infrastructure or JEDI), worth up to \$10 billion over a period of 10 years (Lardinois 2019; Tsidulko 2020), while Google lost against Facebook repeatedly, in the competition for the hegemony over the social business, by shutting down first Orkut, then Google Buzz, and finally Google Plus (Vítečková 2020). It would be interesting to write a history of when multinational giants have failed to beat other multinational giants at their (that is, of the challenged) own game, or have learnt to avoid to compete among each other, because it would be a history of de facto monopolies and how a pax digitalis of non-belligerence emerged

\footnotetext{
${ }^{6}$ In the Greek sense of the kubernetes', that is, the pilot's, ability to navigate and steer, as discussed by Plato in the Republic.

${ }^{7}$ https://www.webfx.com/blog/seo/2019-search-market-share/
} 
among such actors. While waiting for such a history, let us return to the topic of digital sovereignty. We have seen that it is generating some confusion. To orient ourselves, let us take a step back.

Sovereignty is a form of legitimate, controlling power. It is the power of the captain of the ship, to adopt and adapt Plato's cybernetic analogy. The debate about who can exercise it, how, on what, and for what purposes, has contributed to shaping the modern age. This is the period that begins, unanimously and conventionally, in 1492, with the discovery (in the sense of Europeans realising the existence) of America, but that generates controversies about its exact end. Modernity of size $S$ ends with the French Revolution (1789). Size $M$ goes all the way to the Congress of Vienna (1814-1815). The $L$ lasts until the outbreak of the First World War (1914). I prefer the $X L$, which runs until the end of the Second World War (1945). I shall return to the justification of this preference presently. Before, we can now qualify as national sovereignty the controlling power exercised by the State on its territory, on the resources that are found in it, and the people who live there. It is a phenomenon and a concept entirely modern (in the sense of the term just seen) and totally analogue, in terms of time, space, and the physicality of things. But the modern age is over, even in its XL version. And our contemporary age is not just post-modern. This is a characterisation that indicates only what our age is no more, but says nothing about what it actually is (note that XL is the only "size" of modernity that can accommodate post-modernity as a chronologically meaningful category). More informatively, our age is above all the digital age (nobody should be surprised by this taxonomy: technology has always helped us to date periods of human evolution, from the Stone Age to the Iron Age). And in the digital age, the infosphere is not a territory, data are not a finite, scarce, rivalrous, natural, nonrenewable resource like oil (so much the worse for the poor analogy), digital assets are largely private and subject to market forces, and our profiles are created, owned, and exploited not just by states but also by multinationals, which, as the word indicates, are globalised. For all these reasons (and several others, see Floridi (2014, 2020)), the digital age is forcing us to rethink the nature of sovereignty. Modern-analogue sovereignty is still necessary but increasingly insufficient, exactly like the State. Contemporary-digital sovereignty is needed as well, in order to provide effective, democratic forms of control, through appropriate regulation. But who should exercise it de facto and de jure?

The first two decades of the century saw the emergence of a sort of de facto digital corporate sovereignty. It is that form of controlling power that is supported by those who argue that corporate self-regulation is sufficient, that legislative intervention is unwelcome and unnecessary, and that any required checks and balances of corporate digital power will come from a competitive, laissez-faire approach, and market-based equilibria. We saw that this digital corporate sovereignty is built on hegemonic positions or de facto monopolies, which enjoy both poietic and cybernetic power over the digital, and on the shift from the individual as a voter-consumer to the individual as a follower-user. Let me comment on both points.

About the first point, I already mentioned how multinationals fail to compete with each other. The logic of winner takes all, the so-called Matthew effect, dominates contemporary capitalism, especially in the digital industry and network economies. Once cumulative advantages create a monopolistic regime, then there is no real competition, so no real consumer's choice, and therefore no real accountability of the 
companies that dominate specific markets. Time has come to introduce the fifth example to exemplify what I mean.

July 29, 2020: Jeff Bezos (Amazon), Tim Cook (Apple), Sundar Pichai (Google), and Mark Zuckerberg (Facebook) were questioned during a hearing of the House Judiciary Subcommittee on Antitrust, Commercial and Administrative Law on "Online Platforms and Market Power, Part 6: Examining the Dominance of Amazon, Apple, Facebook, and Google." The Chairman David N. Cicilline gave the following opening statement, worth quoting at length:

"[...]. Open markets are predicated on the idea that if a company harms people, consumers, workers, and business partners will choose another option. We are here today because that choice is no longer possible. [...] Because concentrated economic power also leads to concentrated political power, this investigation also goes to the heart of whether we, as a people, govern ourselves, or whether we let ourselves be governed by private monopolies. American democracy has always been at war against monopoly power. Throughout our history, we have recognized that concentrated markets and concentrated political control are incompatible with democratic ideals. When the American people confronted monopolists in the past — be it the railroads and oil tycoons or AT\&T and Microsoft—we took action to ensure no private corporation controls our economy or our democracy. We face similar challenges today. [...] Their ability to dictate terms, call the shots, upend entire sectors, and inspire fear represent the powers of a private government. Our founders would not bow before a king. Nor should we bow before the emperors of the online economy". 8

Corporate digital sovereignty is not just a philosopher's idea, but a political reality. This leads me to the second point about the shift from voters-consumers to followers-users.

In the second half of the twentieth century, democracy and capitalism were seen as two sides of the same coin also because both were assumed to be accountable to people, through competition, which was based on political (voting) and purchasing (buying) choices, respectively. We just saw that Cicilline's statement assumes this premise. It is also implicit in classics such as Von Mises (2005), for example. So, it was coherently (if mistakenly) thought that exporting capitalism would have meant exporting democracy. In particular, it was thought that China would have become a democracy through the Trojan horse of capitalism. It did not work. The two phenomena were merely travelling in parallel for a while, in some Western countries. Whether the misleading narrative was a naive mistake or an evil plan depends on whom you ask and about whom they are talking. The fact remains that popular sovereignty, as the source of legitimisation of political power, including national sovereignty, was seen as the sovereignty of the voter and of the consumer, as if these two roles were intrinsically part of the essence of a citizen, as an indissoluble unity, empowered by competition for people's vote and money. However, since the end of modernity (the XL concept I introduced before), the progressive fulfilment (or at least the hope thereof) of the consumer's desires first stretched and then snapped away from the voter's needs, like two pieces of blu tack. Marx failed to see (or indeed could not have seen what is now

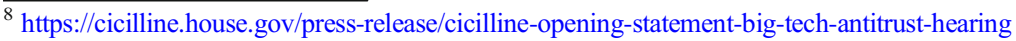


easy to see) that capitalism flourishes by transforming the working class into the shopping class through consumerism, and that to promote consumerism capitalism needs to guarantee a minimum amount of redistribution (or at least creditworthiness) to create an increasing number of customers who can (at least believe to be able to) afford an increasing number of good and services, while fuelling in those customers the hope that the future will always be better than the past (tomorrow is not just another day, it is a better day), when they may join (or defend their newly acquired status as members of) the bourgeoisie, to use Marx's vocabulary. Likewise, liberalism did not see (or again, could not have seen) that the progressive increase in relative prosperity and the hope of future gaining deprioritise political participation and hence the demand for change. In both cases, one may quip that the worst enemy of democracy is a credit card. For democracy is more likely to be the demand of the poor than of the rich, or of those who hope to become rich. However, note that this cuts both ways, because democracy and capitalism are not two sides of the same coin: an economic future worse than the present simply motivates people to ask for political change, and when this happens in a democracy this means that populism arises and democracy is challenged. Our time provides plenty of examples, from Italy to the UK, from the US to Brazil.

In the past decades, increasing prosperity made consumers feel democracy decreasingly essential, as long as the future was economically better than the present. This is also the time of the great decoupling of social sciences from ethics: after the end of modernity (the XL size again), in liberal democracies economy focuses on profit, jurisprudence on compliance, and politics on consensus, while right and wrong are more likely to be treated as a matter of private choices and preferences. Today, we know that it takes a lot of pressure to rebel against a repressive regime, and that such a pressure is relieved by economic growth. Thus, with an oversimplification (because there are many and complex factors at stake, see for example (Roberts et al. forthcoming)), one may jest that in China the cost of democracy is a yearly growth of the GDP of at least $7 \%$ or so: if it is lower than that, then people may start complaining, politically and en masse, because they may want an economically better society through better politics. When it is higher than that, then students, idealists, activists, and few other politically minded people, may be ready to run serious risks for their freedom and life, and protest for a socially better society, but they remain a minority. More generally, autocratic powers will not be overturned by masses that every year can look forward to a better year. This long premise should help to understand a fundamental shift in the role of the individual, who, in this century, has moved from being a voter-consumer, empowered by competition, to being a followeruser, disempowered by political and business hegemonies and consumeristic hopes.

In an age when analogue reality is increasingly managed and controlled by digital reality, the socio-political sovereignty on both appears to be essential for a better democracy, public accountability, and coordinated cooperation to tackle global problems, to make society fairer, and development at least sustainable. In Europe, this means asking who should exercise digital sovereignty, whether each Member State or the European Union. The distinction is important. When Macron and Merkel speak of digital sovereignty, do they mean the national one (France's, Germany's, etc.), or the supranational one (EU's), as when von der Leyen refers to it? The risk, when supporting national digital sovereignty, is to end up supporting digital sovereignism or digital statism. These are culturally and economically anachronistic positions, which 
defend an autarchic and mercantilist version of the digital. They range from the rhetoric of national champions, existing or to be created, to the wishful thinking about cloning foreign successes at home. They should both be resisted. Yet the line that separates them from digital sovereignty can be easily blurred, also in the EU.

In the EU, analogue sovereignty is articulated on two levels. For example, tax sovereignty remains national, to the extent that multinational companies exploit it to game the EU system and play national sovereignties against each other, think of the Apple-Ireland case. ${ }^{9}$ But, continuing with the example, monetary sovereignty in some cases has become supranational, whenever Member States have adopted the euro. Likewise, digital sovereignty should probably be equally articulated, with both national and supranational levels of implementation. In some fundamental cases, also in view of avoiding digital sovereignism and statism, digital sovereignty could be exercised more easily by the EU, both in terms of feasibility and in terms of added value, resembling the case of monetary sovereignty and what has happened with the Eurozone. We know, for example, that digital data sovereignty is more feasible and effective at the EU level, through the General Data Protection Regulation. It may be reasonable to move in the same direction with regard to AI sovereignty and $5 G$ sovereignty, to mention two other key digital areas. Because the best answer to the multinationals' control of the digital is probably the establishment of a (de jure and not only a possibly de facto) supranational digital sovereignty, at the EU level.

The debate on digital sovereignty is not about replacing national modern-analogue sovereignty, which is necessary but increasingly insufficient. It is about complementing it with a supranational, contemporary-digital one-which is often its condition of possibility - also to provide to all actors and stake-holders wider benefits of harmonisation (e.g. standards and requirements) and level playing field, as well as to enhance opportunities of coordination. But if this is the case, as I would argue, then at least one more significant problem still remains to be solved: legitimacy (Schmitter 2001).

Recall that, if (not yet qualified) sovereignty is the controlling power that legitimises (transforms power into recognised authority) other forms of power but requires no previous controlling power to be legitimised in its turn, then national sovereignty is usually based on popular sovereignty, which is taken to be a sort of Aristotelian unmoved mover. The regressus ad infinitum is avoided by having individuals pooling their self-sovereignties (sovereignty on themselves) through deliberation, negotiation, and voting, to create popular sovereignty, which then legitimises national sovereignty, which then controls individuals' legal exercise of their self-sovereignties. The answer to "quis custodiet ipsos custodes?" is the "custodiendi" themselves as a group (who controls the controllers? The controlled themselves). This is not a vicious circle but a virtuous spiral, given the shift from individual sovereignty (self-sovereignty) to societal sovereignty (popular sovereignty). Through their lives, individuals join a polity, which is more stable than their existence, and as they come and go, like many short fibres of a rope, they make the rope (popular sovereignty) long and strong. The question is what happens when digital or analogue sovereignty is no longer national but supranational: how can the support of popular sovereignty be expanded to cover also supranational sovereignty? And indeed, can it be? There seem to be several alternatives, sometimes

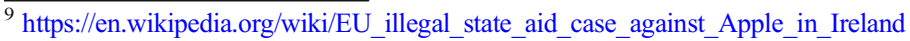


defended and criticised in the EU under the general topic of "democratic deficit". In each alternative, popular sovereignty remains the ultimate source of legitimisation of all other forms of sovereignty, including national and supranational sovereignty. What is controversial is how exactly this may work.

One way forward is to recall that sovereignty is not like a rivalrous resource that, when given to someone is no longer in one's possession, and can only be reacquired by taking it back from that someone. It is more like a relation (control), in which one may engage more or less intensely and successfully, but precisely because it is a matter of engagement is never "lost" when exercised or delegated, and is not finite or rivalrous: giving it to someone does not mean being unable to give it also to someone else at the same time. Such a relational concept of sovereignty enables one to see that the legitimisation of sovereignty can be modelled in terms of the topology of the network that seems to be the most appropriate for its structuring. Many network topologies are possible in theory, but three are of political and historical interest here.

In a fully connected network topology, each node enjoys popular + national sovereignty, and the nodes are all linked together for some common purposes. Each node is legitimised by its own popular sovereignty, each node can leave the network at any time (secession), and the network itself lacks its own legitimacy over and above the legitimised nodes. This more distributed legitimacy is what some supporters of a European confederation of national states (the nodes), for example, seem to have in mind. It can be a strong version of intergovernmentalism, which can deal with fundamental issues such as currency, trade, or defence. But in terms of political design, this network requires no innovation: it is simply a more or less strong network of Westphalian states. As a modern concept, it is well established in terms of common action among sovereign states that pursue shared goals and wish to further shared aims. Since it requires no changes in popular or national sovereignty, it also requires no storytelling to be made popular among voters.

In a star network topology (think of spoke-hub distribution), popular sovereignty is placed at the centre and legitimises directly every other peripheral node, represented by other kinds of sovereignty, national and supranational included. The network has its own supranational sovereignty. This more centralised legitimacy is what some supporters of a European federation, for example, seem to have in mind. It is simple and classic, in terms of political design, representing an updating of the Westphalian state to a federated version, and perhaps for this reason also easier to understand, but it may not be popular among voters attached to nationalistic values and policies.

Finally, in a hybrid topology of a partially connected mesh, there can be nodes, popular sovereignties, that legitimise other nodes, national sovereignties, which then legitimise some other nodes, e.g. supranational sovereignties, possibly in a mutually legitimising relation. This more hierarchical legitimacy is what some supporters of a multi-speed Europe, for example, seem to have in mind. Its variable geometry is less intuitive and more innovative in terms of political design. It is also more complex and difficult to implement properly, and because it is largely unprecedented it requires more and better story-telling to be explained and made popular. But it is not hard to conceptualise, because states can be fruitfully understood today as individual multiagent systems (Floridi 2015, 2016) that pool and transfer their national sovereignties to create supranational sovereignty in some areas. We saw that the Eurozone provides an excellent example. So, one may argue that popular sovereignty (understood as the pooling of 
individuals' self-sovereignties) legitimises national sovereignty as national sovereignty (now understood as the pooling of national multiagent systems self-sovereignties) legitimises supranational sovereignty. This is how the "combined sovereignty" of the EU may be understood and promoted. Through the mechanism of "enhanced cooperation", ${ }^{10}$ a hybrid network could support a core of more federal Europe within a larger, more confederated EU, and call the whole the United States of Europe. ${ }^{11}$

Perhaps a EU that currently has different solutions for different kinds of analogue sovereignty and only the beginning of some kinds of digital sovereignty may one day opt, as plan A, for a centralised, single form of both analogue and digital sovereignty. However, this seems to be unlikely and at best a very distant in the future, even assuming it is a preferable strategy. The good news is that this is also not incompatible with an EU that continues to opt, for the foreseeable time, in favour of variable geometries of both analogue and digital sovereignty. For some people, this hybrid topology will remain plan B, with the advantage of feasibility and the shortcomings of a compromise but I would like to argue that it should rather be the focus of some truly innovative design, to transform it into a successful plan A. Because a partially connected mesh of individual, popular, national, supranational, and subnational (see for example the case in support of indigenous data sovereignty, (Taylor and Kukutai 2016)) sovereignties, both analogue and digital, could deliver full democratic legitimacy and great innovative flexibility, if designed successfully. Not an easy thing to do, but, if I am correct, one day the United States of Europe will not be an intergovernmental or supranational chapter in the history of the Westphalian state and its analogue/ digital sovereignties, but a new book altogether, neither a confederation nor a federation, but a differentiated integration with its own design.

But enough about a possible future. Let me close with a look at the past, and a historical comparison almost entirely incorrect. The fight for digital sovereignty may remind one of the Investiture Controversy, the medieval conflict between the Church/ Pope and the State/Emperor in Europe over the ability to choose and install bishops and more generally over secular and spiritual power. Of course, that controversy is very different from anything we are seeing in the fight for digital sovereignty. But I wrote that the comparison is not entirely incorrect. That controversy was a significant stage in the development of the concept of sovereignty, as the etymology of the word makes obvious. Today, the fight is not over secular and spiritual power but over corporate and political power over the digital, yet the roots of this clash are very old. But most importantly that mediaeval debate reminds us that whoever will win the fight for digital sovereignty will determine the lives of all people on both sides of the digital divide, exactly like the Investiture Controversy affected all people, no matter whether religious or not. This is why I begun this article by saying that digital sovereignty is not just a matter of interest for some specialists. It is already affecting everybody. And this is why it is essential to design it as well as possible, together.

Acknowledgements I benefitted enormously from several conversations with many members of the Digital Ethics Lab, and above all with Josh Cowls, Hugh Roberts, and Mariarosaria Taddeo, who read a penultimate

\footnotetext{
${ }^{10} \mathrm{https}: / /$ en.wikipedia.org/wiki/Enhanced_cooperation

${ }^{11}$ See for example the proposal made by Guy Verhofstadt, MEP and former Belgian prime minister (Verhofstadt 2006).
} 
version of this article and provided some truly excellent suggestions on how to improve it substantially. They are of course not responsible for any remaining mistake.

\section{References}

Burgess, M. (2020). Why the NHS Covid-19 contact tracing app failed. Wired.

Busvine, D., \& Rinke, A. (2020). Germany flips to Apple-Google approach on smartphone contact tracing. Reuters.

Clayton, J. (2020). "TikTok: Chinese app may be banned in US, says Pompeo." $B B C$.

Floridi, L. (2014). The fourth revolution - How the infosphere is reshaping human reality. Oxford: Oxford University Press.

Floridi, L. (2015). "Hyperhistory and the philosophy of information policies." In The Onlife Manifesto: Being human in a hyperconnected era, edited by Luciano Floridi, 51-63. Cham: Springer International Publishing.

Floridi, L. (2016). Hyperhistory, the emergence of the MASs, and the design of infraethics. In In Information, freedom and property: The philosophy of law meets the philosophy of technology, edited by Mireille Hildebrandt and Bibi van den berg, chapter 7. London: Routledge.

Floridi, L. (2020). Il Verde e Il Blu - Idee ingenue per migliorare la politica. Milano: Raffaello Cortina.

Lardinois, F. (2019). "In a victory over Amazon, Microsoft wins \$10B pentagon JEDI cloud contract." Tech Crunch.

Lomas, N. (2020). "Germany ditches centralized approach to app for COVID-19 contacts tracing." Tech Crunch.

Longo, A. (2020). "L'app Immuni cambia. Seguirà il modello decentralizzato di Apple e Google." Il Sole24Ore.

Morley, J., Cowls, J., Taddeo, M., \& Floridi, L. (2020). Ethical guidelines for COVID-19 tracing apps. Nature, 582, 29-31.

Mukherjee, S. (2020). China may retaliate against Nokia, Ericsson if EU bans Huawei: WSJ. Reuters.

Posner, M. (2020). What's behind the trump-twitter clash? Forbes.

Roberts, H., Cowls, J., Morley, J., Taddeo, M., Wang, V., and Floridi, L. (forthcoming). "The Chinese approach to artificial intelligence: An analysis of policy and regulation." AI \& Society.

Schmitter, P. C. (2001). "What is there to legitimize in the European Union... and how might this be accomplished?" Working Paper, Wien, Institut für Höhere Studien, 2001, Political science series, 75IHS Working Papers, 2001 https://jeanmonnetprogram.org/archive/papers/01/011401-01.html.

Singh, M. (2020). India bans TikTok, dozens of other Chinese apps. Tech Crunch.

Taylor, J., and Kukutai, T. (2016). "Indigenous data sovereignty: Toward an agenda." In. Acton, ACT, Australia: Australian National University Press.

Tsidulko, J. (2020). Pentagon CIO: JEDI cloud 're-announcement' should come by end of August. CRN.

Verhofstadt, G. (2006). The United States of Europe: Manifesto for a new Europe. London: Federal Trust for Education and Research.

Vítečková, K. (2020). The story behind Google Plus shutting down. Wiredelta.

Von Mises, L. (2005). Liberalism: The classical tradition, Liberty Fund Library of the works of Ludwig Von Mises. Indianapolis: Liberty Fund.

Publisher's Note Springer Nature remains neutral with regard to jurisdictional claims in published maps and institutional affiliations. 